\title{
Research on modeling of electric power transaction process based on block chain technology
}

\author{
Qingli Hao ${ }^{1, *}$, Guolong Yin ${ }^{2}$, Pengtao Xu${ }^{1}$, Chao Zhang ${ }^{2}$, Xiaozhen $\mathrm{Ma}^{2}$, Jing Zhang ${ }^{2}$, Yongbing Yan ${ }^{1}$ and Hongjie Tian ${ }^{2}$ \\ ${ }^{1}$ Beijing Zhongdian Puhua Information Technology Co., Ltd., Beijing, 100085, China \\ ${ }^{2}$ Ningxia Power Exchange Center Co., Ltd., Yinchuan,750003, China
}

\begin{abstract}
Block chain technology is one of the optional technologies for the realization of intelligent power transactions on the residential side, and the specific transaction process is lacking research. Based on the composition of the block chain and its technical characteristics, this paper proposes a typical transaction flow for market participants in the electricity transaction under the environment of the residential side open electricity market based on block chain technology. According to the needs of power trading, the power trading using block chain technology is divided into 7 steps and abstracted separately. Finally, the power transaction based on block chain technology is analyzed, and the transaction process is further explained in combination with the case, which provides a reference for the introduction of new technologies for the design of ubiquitous power internet of things power transactions.
\end{abstract}

\section{Combination of power trading and block chain technology}

Block chain technology is considered to be a technology that lowers the threshold for trading entities to participate in the market. The distributed sharing of current transaction data can be used as an innovative technology to promote the distributed development of the energy industry ${ }^{[1-2]}$. Literature ${ }^{[3]}$ presents a market mechanism that combines block chain technology to implement user-side distributed power transactions. Literature ${ }^{[4]}$ presents a new model that combines block chain technology to realize power user demand-side resource transactions.

\subsection{Block chain technology}

Block chain technology has been proposed as the underlying technology of bitcoin. after more than 10 years of development, its application has long been not limited to the issuance and payment of virtual currency. more, it focuses on the research and development of consensus mechanism, intelligent contract, decentralized data sharing and non-tampering characteristics to achieve value interconnection and distributed intelligent application ${ }^{[5-6]}$.Block chain technology can realize distributed data sharing and intelligent value transfer, which is determined by special data generation, data transmission and data storage mechanism, which can ensure the undifferentiated sharing and non-tampering of data. The special data mechanism is due to the introduction of consensus mechanism, encryption algorithm, shared account book, intelligent contract, identity authentication and other technologies .

\subsection{Electric power transaction}

The main players of the electricity side market in the power Internet of things need to be brought into the market category with the assistance and guidance of the power trading center, which can be mainly divided into three levels of application categories ${ }^{[7-8]}$ :

(1) The infrastructure layer, which guarantees the execution of electric power transaction, including transmission and distribution company, communication company and electrical equipment maintenance company, etc., which is the premise to guarantee the execution of electric power transaction;

(2) The transaction layer (application layer), which is the main body of electricity market operation, mainly includes the sale of e-commerce, auxiliary service providers, generators, ordinary power users and production and consumption users, is the key to carry out electric power transaction;

(3) The financial layer, which provides supporting settlement and value transfer services for electricity transactions, mainly including traditional banks, mobile payment platforms and small and micro crowdfunding platforms, is the driving force for the implementation of electricity transactions.

\subsection{Analysis of the value of block chain technology for electricity transactions}

Table 1. Analysis of the value of block chain technology for electricity transactions.

\begin{tabular}{c|c|c}
\hline $\begin{array}{c}\text { Technical } \\
\text { items }\end{array}$ & $\begin{array}{c}\text { Analysis of technical } \\
\text { value in power trading }\end{array}$ & $\begin{array}{c}\text { Specific } \\
\text { technical }\end{array}$
\end{tabular}

* Corresponding author's e-mail:xl1124213797@,163.com 


\begin{tabular}{|c|c|c|}
\hline $\begin{array}{l}\text { Consensus } \\
\text { mechanism }\end{array}$ & $\begin{array}{l}\text { As a prerequisite for the } \\
\text { rapid completion of } \\
\text { power transactions } \\
\text { between market entities, it } \\
\text { can reduce the } \\
\text { certification time of } \\
\text { power transactions, } \\
\text { optimize the process of } \\
\text { power transactions, and } \\
\text { improve the efficiency of } \\
\text { trading }\end{array}$ & $\begin{array}{l}\text { application } \\
\text { Set up the } \\
\text { operation } \\
\text { regulation of } \\
\text { power trading } \\
\text { application } \\
\text { platform, } \\
\text { guide power } \\
\text { trading to } \\
\text { operate } \\
\text { according to } \\
\text { the unified } \\
\text { mechanism }\end{array}$ \\
\hline $\begin{array}{l}\text { Intelligent } \\
\text { contract }\end{array}$ & $\begin{array}{l}\text { To meet the market } \\
\text { participants' personalized } \\
\text { demand for electricity in } \\
\text { the electricity trading } \\
\text { market }\end{array}$ & $\begin{array}{l}\text { Configure } \\
\text { automatic } \\
\text { algorithms } \\
\text { for data } \\
\text { processing of } \\
\text { power trading } \\
\text { application } \\
\text { platform }\end{array}$ \\
\hline Sharing books & $\begin{array}{l}\text { Under the environment of } \\
\text { balanced and open power } \\
\text { market, the data } \\
\text { information between } \\
\text { market entities and the } \\
\text { data of the Shared system } \\
\text { without difference }\end{array}$ & $\begin{array}{l}\text { Data support } \\
\text { for } \\
\text { distributed } \\
\text { data storage } \\
\text { and } \\
\text { transaction } \\
\text { validation } \\
\end{array}$ \\
\hline $\begin{array}{l}\text { The encryption } \\
\text { algorithm }\end{array}$ & $\begin{array}{l}\text { Strengthen the } \\
\text { information security } \\
\text { protection within the } \\
\text { private chain, prevent the } \\
\text { power trading data from } \\
\text { being tampered, maintain } \\
\text { the security of the trading } \\
\text { and the integrity of the } \\
\text { data }\end{array}$ & $\begin{array}{c}\text { System data, } \\
\text { transaction } \\
\text { data, } \\
\text { operation log } \\
\text { data } \\
\text { processing }\end{array}$ \\
\hline $\begin{array}{l}\text { The identity } \\
\text { authentication }\end{array}$ & $\begin{array}{l}\text { Set the entry threshold of } \\
\text { market participants to } \\
\text { improve the } \\
\text { confidentiality level of } \\
\text { internal transactions }\end{array}$ & $\begin{array}{l}\text { Build small } \\
\text { scope, } \\
\text { personalized } \\
\text { power trading } \\
\text { platform } \\
\text { application }\end{array}$ \\
\hline
\end{tabular}

\section{Power transaction process based on block chain}

The application of power transaction based on block chain technology can be divided into seven stages according to the order: initiating power transaction, transaction matching, transaction authentication, transaction execution, execution result authentication, clearing and settlement, and transaction data storage.

(1) Initiation and declaration

The transaction data reported by the block chain power trading application terminal will be automatically suffixed with a block header information currently forming a block:

$$
\left\{\begin{array}{l}
F_{i}(\text { Header })=N \text {-version } \mid \text { Timestamp } \| \text { Noce } \| \text { bits } \mid F_{i}(\text { Merkle }) \\
F_{(}(\text {Body })=F(\text { Merkle })=f(\text { hash } 1)=I n p u t\left(P, C_{i, i}\right.
\end{array}\right.
$$

In the formula, $N$-version represents the version number of block $n$; Timestamp is the time stamp, which records the formation time of the block; Noce is the random number initiated by the transaction and a series of random numbers encrypted by hash function; bits is the target hash value of the current transaction; Merkle is the block head pointer root of the input transaction function; $f($ hash 1$)$ is the request function of transaction 1 encrypted in hash mode; Input $\left(P_{i, A l}, \mathrm{C}_{i, A l}, T_{i, A l}\right)$ is the data of input transaction 1 encrypted by hash function, $P_{i, A l}, \mathrm{C}_{i, A l}, T_{i, A l}$ are the trading volume, price and trading time respectively.

(2) Transaction matching

According to the system monitoring data, the application platform of block chain technology matches the data of the main body of the electricity market. The transaction order is formed between the power users who have successfully matched. The transaction order is signed and confirmed by both parties using the private key, and the power transaction order is generated after it takes effect.

$$
\left\{\begin{array}{c}
\Delta C_{\min }=C_{i, O}-C_{j, A} \\
\Delta C_{\text {min }} \geq 0
\end{array} \quad i \neq j, i, j=1,2, \cdots, \mathrm{n}\right.
$$

In the formula, $C_{i, O}$ is the seller's quotation; $C_{j, A}$ is the buyer's quotation; $\Delta C_{\min }$ is the minimum difference between the seller's and the buyer's quotation; $i, j$ is the node number of power users on the block chain network.

(3) Matching authentication

The electric power transaction matching authentication is divided into two stages. The first stage is the confirmation of the transaction order data by the market entities of both sides of the transaction matching, which can be expressed as formula 3; the second stage is for the participants of the system to confirm the transaction order. In the second stage, the execution of the transaction order is verified by running the smart contract locally. The transaction order that passes the verification is signed with its own public key, which is shown in formula 4.

$$
\begin{gathered}
F=N \text {-version } \mid \text { Inputnum }|| \text { Input }\left(P_{i, A l}, C_{i, A l}, T_{i, A l}\right) \mid \\
\mid \text { Outputnum }|| \text { Output }\left(P_{i, B l}, C_{i, B l}, T_{i, B l}\right) \mid \\
F_{\text {pass }}=F_{i} \sum \operatorname{sign}(i-\text { pubkey })
\end{gathered}
$$

In the formula, Inputnum is the block header content of the transaction initiating user;Outputnum is the version content in the block header of power selling user B; Output $\left(P_{i, B l}, C_{i, B l}, T_{i, B l}\right)$ is the transaction function of the private key signature of the successful power seller $\mathrm{B} ; P_{i, B l}, C_{i, B l}, T_{i, B l}$ refer to the trading volume, price and trading time data of electricity selling user B participating in the transaction; $\operatorname{sign}(i-p u b k e y)$ is the public key information signed 
by the system participant I after the transaction order is authenticated.

(4) Execution of electricity trading

The electricity trading orders that have passed the certification will be distributed to all market entities. The power transaction is executed strictly according to the power transaction order. The system monitoring equipment records the transmission and distribution parameters in real time, mainly including voltage, frequency, electric quantity and corresponding time. When the execution of power transaction is blocked at the power consumption side, the corresponding transaction order will be cancelled according to the emergency mode, and then the accountability assessment will be carried out afterwards.

(5) Power execution result certification

The block chain power trading platform collects the results of power transaction order execution authentication. When the execution list cleared by the platform is inconsistent with the result of joint verification by market entities, the result of joint verification by market entities shall prevail. 51\% consensus mechanism is adopted for the results of market participants participating in the verification of electricity trading results, that is, when more than $51 \%$ of the nodes in the market entities pass the authentication, the results of authentication are valid results, as shown in formula 5 .

$$
\operatorname{Num}\left[\operatorname{sign}\left(F_{i}, \text { pass }\right)\right]>\operatorname{Num}\left[\operatorname{sign}\left(F_{i}, \text { oppose }\right)\right]
$$

In the formula, $\operatorname{Num}\left[\operatorname{sign}\left(F_{i}\right.\right.$, pass $\left.)\right]$ is the number of nodes in the chain that the authentication transaction passes; $\operatorname{Num}\left[\operatorname{sign}\left(F_{i}\right.\right.$,oppose $\left.)\right]$ is the number of nodes in the chain that failed the authentication transaction.

(6) Clearing the trading results

After the power transaction execution result is authenticated, the transaction execution result data is generated. Finally, the block chain application platform clears the transaction result information of the last transaction period and stores it in a distributed way.

(7) Settlement and transfer price

Value payment can be expressed as formula 6 , subject $A$ is the original value owner; subject $B$ is the current value owner, and the value source receives the value payment from subject $A$; the receiver of subject $C$ receiving the value payment of subject $B$ will have the payment value.

$$
\left\{\begin{array}{c}
F_{A}=f(\operatorname{scriptSign}(A))_{B_{-} I D} \\
F_{A \rightarrow B}=f\left(F_{A}, \text { scriptPubkey }(B)\right)_{C_{-} I D} \\
F_{B \rightarrow C}=f\left(F_{A \rightarrow B} \operatorname{scriptSign}(B), \text { scriptPubkey }(C)\right)
\end{array}\right.
$$

In the formula, $F_{A}$ is the fund output function of node user A; scriptSign $(A)$, scriptPubkey $(B)$ encrypts the fund signature for user nodes A and B; $F_{A \rightarrow B}$ is the transfer of funds from node user A to node user B; scriptPubkey $(B)$, scriptPubkey $(C)$ is for node users $\mathrm{B}$ and $\mathrm{C}$ to decrypt funds with public key; $B{ }_{-} I D, C_{-} I D$ is the node address information of node $\mathrm{B}$ and $\mathrm{C}$ with suffix.

\section{Case study}

Using the power-consumption-side market environment established by block chain technology to build a power trading application platform with a balance of power and responsibility can integrate power suppliers and market entities, and mobilize supply-side resources and demandside resources in a safe and orderly manner to achieve benign interaction, so that The utilization efficiency of supply-side resources and demand-side resources is maximized.

Process application case analysis combined with block chain power transaction application process, This paper takes the purchase of electric energy from the market main body B the market main body A as an example to analyze the electricity side power transaction based on block chain technology, The owner B purchase $10 \mathrm{~kW} \cdot \mathrm{h}$ of electricity from the owner for 0.67 yuan/(kWh) during a trading cycle. The blocks generated at each stage of the electricity transaction are shown in Table 2. In which the power transaction execution phase generates system monitoring data, not do summary presentation in the table.

\begin{tabular}{|c|c|c|c|}
\hline Stage & $\begin{array}{c}\text { Time } \\
\text { interval } \\
\text { /min }\end{array}$ & Block head & $\begin{array}{c}\text { Block body content } \\
\text { summary }\end{array}$ \\
\hline 1 & {$\left[\mathrm{t}_{0}, \mathrm{t}_{1}\right)$} & $\begin{array}{l}\text { vision. } 123000 \\
010 . \text { Nounce }_{1} . \\
\text { bits }_{1}\end{array}$ & $\begin{array}{c}\text { Input } \\
(10 \mathrm{~kW} \cdot \mathrm{h}, 0.67 \mathrm{yan} /(\mathrm{kW} \cdot \mathrm{h}), 500)\end{array}$ \\
\hline 2 & {$\left[\mathrm{t}_{1}, \mathrm{t}_{2}\right)$} & $\begin{array}{l}\text { vision. } 123000 \\
010 . \text { Nounce }_{2} . \\
\text { bits2 }\end{array}$ & $\begin{array}{c}\text { Output } \\
(10 \mathrm{k} W \cdot h, 0.67 y u a n /(k W \cdot h), 500)\end{array}$ \\
\hline 3 & {$\left[\mathrm{t}_{2}, \mathrm{t}_{3}\right)$} & $\begin{array}{l}\text { vision. } 123000 \\
010 . \text { Nounce } 2 . \\
\text { bits } 3\end{array}$ & $\operatorname{sign}(i-p u b k e y)$ \\
\hline 4 & {$\left[\mathrm{t}_{3}, \mathrm{t}_{4}\right)$} & $\begin{array}{l}\text { vision. } 123000 \\
\text { 010.Nounce } 3 . \\
\text { bits } 3\end{array}$ & $\operatorname{Num}($ pass $)>\operatorname{Num}($ fail $)$ \\
\hline 5 & {$\left[\mathrm{t}_{4}, \mathrm{t}_{5}\right)$} & $\begin{array}{l}\text { vision. } 123000 \\
\text { 010.Nounce } \\
\text { bitsn }\end{array}$ & 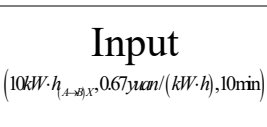 \\
\hline 6 & {$\left[\mathrm{t}_{5}, \mathrm{t}_{6}\right)$} & $\begin{array}{l}\text { vision. } 123000 \\
\text { 010. Nounce } \\
\text { bitsz }\end{array}$ & $(6.7 \text { yuan })_{B \rightarrow A},(0.2 y \text { uan })_{B \rightarrow X}$ \\
\hline
\end{tabular}

Table 2. Abstract information table of case block 


\section{Conclusions}

This paper applies block chain technology to power trading on the power side, proposes a typical process of power trading based on the framework of block chain technology, combines the characteristics of block chain technology and power trading, and designs a general process of power trading based on block chain technology based on the financial application of block chain technology. It should be pointed out that this paper is based on the technical characteristics of the block chain to explore the general trading process of power transactions. But the electricity transaction on the power side is affected by the policy, the market main body, the resource allocation and so on. Therefore, the power transaction based on block chain technology needs to keep up with the policy and market demand, and actively adjust the transaction process design.

\section{References}

1. Kim M, Song S, Jun M S. A study of block chainbased peer-to-peer energy loan service in smart grid environments[J]. Advanced Science Letters, 2016, 22(9):2543-2546.

2. Zeng Ming, Chen Jun, Wang Yuqing,et al. Energy Internet under the framework of block chain preliminary study on multi-module collaborative autonomy mode $[\mathrm{J}]$. Chinese journal of electrical engineering,2017,37(13):3672-3681.

3. Ping Jian, Chen Sijie, Zhang Ning,et al. Distribution contract decentralized transaction mechanism based on smart contract[J]. Chinese journal of electrical engineering,2017,37(13):3682-3690.

4. Wu Geng,Zeng Bo,Li Ran,et al. Research on application mode of block chain technology in comprehensive demand side response resource transaction[J]. Chinese journal of electrical engineering,2017,37(13):3717-3728.

5. Beck R, Stenum C J, Lollike N, et al. Blockchainthe gateway to trust-free cryptographic transactions. in: european[C]//Conference on Information Systems, p, 2016: 1-14.

6. Ji Bin, Tan Jiancheng.Preliminary research of distributed micro-energy trading on Power distribution side using blockchain technique[J].Modern power, 2019,36(01):29-36.

7. Li Chunta, Weng Chiyao, Lee Chengchi, et al. A hash based remote user authentication and authenticated key agreement scheme for the integrated EPR information system[J]. Journal of Medical Systems, 2015, 39(11): 144.

8. Zhun Runnong.Research on Electricity Trading Platform Based on Block chain[D].Changsha University of Science and Technology,2018. 